\section{More Medical Research}

The budget of the Medical Research Council for 1965-66 was comfortably greater than that in the preceding year. According to the annual report now published, $£ 11$ million were spent in 1965-66 compared with $£ 9.6$ million in $1964-65$, an increase of roughly 15 per cent. More than 90 per cent of the council's income consists of a parliamentary grant and another $£ 770,000$ is provided by government departments and public bodies in return for services rendered. The council spends most of its income on the current expenses of research units and laboratories throughout the United Kingdom and a comparatively small amount- $£ 373,000$ in 1965-66-on new buildings. The National Institute for Medical Research at Mill Hill, London, accounts for one-eighth of the total budget, roughly a half of which, or more than $£ 5$ million, is spent on research units and external scientific staff.

The council is clearly pleased with developments at the Clinical Research Centre at Northwick Park in North London. The annual report recalls that in the late fifties the council decided there was a need for a clinical research centre in Britain bringing together "clinical and para-clinical workers". The Northwick Park centre is being built in collaboration with the North West Metropolitan Regional Hospital Board. It will consist of a research institute, a laboratory, lecture hall, and accommodation for patients. The research institute itself will be a substantial building with $100,000 \mathrm{sq}$. ft. of space, and there will also be supporting facilities-an animal house, workshops, and so on. One wing of the hospital ward block, containing 140 beds, has been specially designed to meet the needs of research workers, principally by incorporating research laboratories into the main structure of the hospital. The annual report for 1965-66 records that Professor G. M. Bull of Queen's University, Belfast, has been appointed director-designate of the centre and that Dr. Richard Doll, of the M.R.C. Statistical Research Unit, has been appointed deputy director. Professor Bull is principally interested in renal and tropical diseases and the study of the balance of electrolytes within the body. Dr. Doll has won a considerable reputation by his statistical analysis of the aetiology of various kinds of cancer and of peptic ulcers.

As in previous years, the annual report also includes a review of the work of the various laboratories and research centres which the council supports. There is also a record of the council's involvement with public affairs, and in particular a reminder that it was primarily responsible for providing the Home Office with the information and advice on which it was actually decided to introduce legislation about the permissible content of alcohol in the blood of car drivers.

According to the report, the total staff of the Medical Research Council was 3,410 at the beginning of 1966 . There were 809 scientific staff and 1,402 technical staff, and the total includes the personnel of the 79 research units (four of them abroad) which were in being at the end of the financial year. In the course of 1965-66 one unit (for obstetric medicine at Aberdeen) was closed on the retirement of the director, and three were established at Newcastle (the Reproduction and Growth Research Unit), Aberdeen (the Medical Sociology Research Unit) and at Hammer- smith (the Cardiovascular Research Unit). During the same year the council undertook to support ten new research groups, bringing the total to 40 . A research group differs from a unit, in the council's terminology, in that its staff is employed by the university or hospital concerned, which also agrees to relieve the council of financial responsibility within five years.

\section{Porter of the R.I.}

Professor George Porter formally took up his post as Director of the Royal Institution on September 1, and his chemical research group is expected to take up quarters in the Davy-Faraday Laboratory within a week or so. Preparations for the arrival of Professor Porter and his team have been under way for some time, and substantial alterations have been made to the laboratories and the domestic rooms at the building in Albemarle Street. The members of the institution plan to welcome Professor Porter and to say goodbye to the retiring director, Sir Lawrence Bragg, when the latter returns from the United States in the autumn.

The immediate effect of the change of directors will be a shift in the emphasis of the research programme at the laboratory away from X-ray crystallography, which has been dominant there for several decades. Since the War the Royal Institution has housed the work of Professer J. D. Bernal on the structure of silicates, that of Dame Kathleen Lonsdale on the structure of ice and diamonds and, recently, that of Professor D. C. Phillips on lysozyme. This tradition of X-ray crystallography has, of course, been fostered in the past seven years by the distinction of Sir Lawrence Bragg in that field. Professor Porter has been concerned with flash photolysis at the University of Sheffield, though his career has been varied. In the mid-fifties he spent some years as deputy director of the British Rayon Research Association in between academic appointments at Cambridge and Sheffield.

The question of how the change of directors will affect the outward activity of the Royal Institution is probably more absorbing and more important, though at this stage there is only guesswork to go on. Sir Lawrence Bragg has sought to carry out the task of conveying science to the public by building up a series of lectures on science for schoolchildren-without, of course, diminishing the importance attached by the members of the Royal Institution to the ceremonial lectures on Friday evenings in season. It would be in character if Professor Porter aimed at an older age group. The fact that he does well on television may be a clue to what will happen, although Sir Lawrence Bragg has been no mean performer. But these are only details. The central question is the one that has faced directors at the Royal Institution for the past thirty years-how to make full use of the plant, and make a real bite on public awareness of science, without seriously disturbing the traditions of the place, jealously guarded as they are.

\section{Research in Japan}

JAPAN maintains itself as a major industrial power even though research expenditure there falls short of that of any other highly industrialized nation. Expenditure in 1964 was $£ 438$ million, representing 